\title{
Geotechnical failure of a slope featuring site development with industrial facilities caused by irresponsible leveling in the neighboring area
}

\author{
Maciej Kordian Kumor ${ }^{1, *}$, and Lukasz Aleksander Kumor ${ }^{1}$ \\ ${ }^{1}$ University of Technology and Life Sciences, 7 Kaliskiego Street, PL 85-386 Bydgoszcz, Poland
}

\begin{abstract}
The article describes an unusual geotechnical failure of properly built-up top backfill of a slope of the subsoil of an industrial facility. The failure was caused by an irresponsible correction of the slope and its base in the neighboring area. Deterioration of the slope built from expansive clay consisted in clearing trees and deep changes in morphology in part of the slope of the neighbor, situated below it. Therefore, arbitrary actions led to a serious geotechnical failure as a result of loss of stability of slopes, an inversion in water relationships going beyond the local area, and change in the direction of flow of surface waters.
\end{abstract}

\section{Introduction}

Proper and complete geotechnical investigation of the subsoil and adjustment of design solutions to the actual geological conditions should in every case guarantee a long-term, safe use of buildings. Usually, the building law in complex or complicated soil and water conditions, second/third geotechnical category, requires from the designer detailed determination and investigation of the subsoil. Polish construction regulations do not oblige investors to investigation of soil and water conditions, particularly on the neighboring lots that are not their property. In addition, in the immediate proximity of the lots that have already been built up, with the exception of special cases, there is no ban on performance of geotechnical works related to changes in the previous use of area by their owners. In many cases seen in practice, we can notice a significant variability of changes, bordering on lawlessness shown by owners in adjustment of the bordering area, through - for instance implementation of new projects. On many occasions, activities are conducted by-passing a law, without any attempts to hide from the discerning eye of construction inspectors.

The article features a typical geotechnical failure of a properly formed and built up subsoil of an industrial facility, serving as the top backfill of the slope. Disturbance of stability was caused by arbitrary and improper change in the angle of inclination of the slope, including undercutting of the base outside the boundaries of the lot, in the neighboring area. Clearing trees that was performed without any permits by the neighbor as well as earthworks and leveling led to a significant geotechnical failure, an inversion in water relationships going beyond the local area, change in the direction of flow of surface waters and destruction of underground infrastructure.

\footnotetext{
* Corresponding author: maciej.kumor@engeo.com.pl
} 


\subsection{Location and description of the site with slope failure}

\subsubsection{Description of the site and location}

The analyzed geotechnical failure was reported on the lot with reference number 15/10, developed with industrial facilities, Fig. 1.

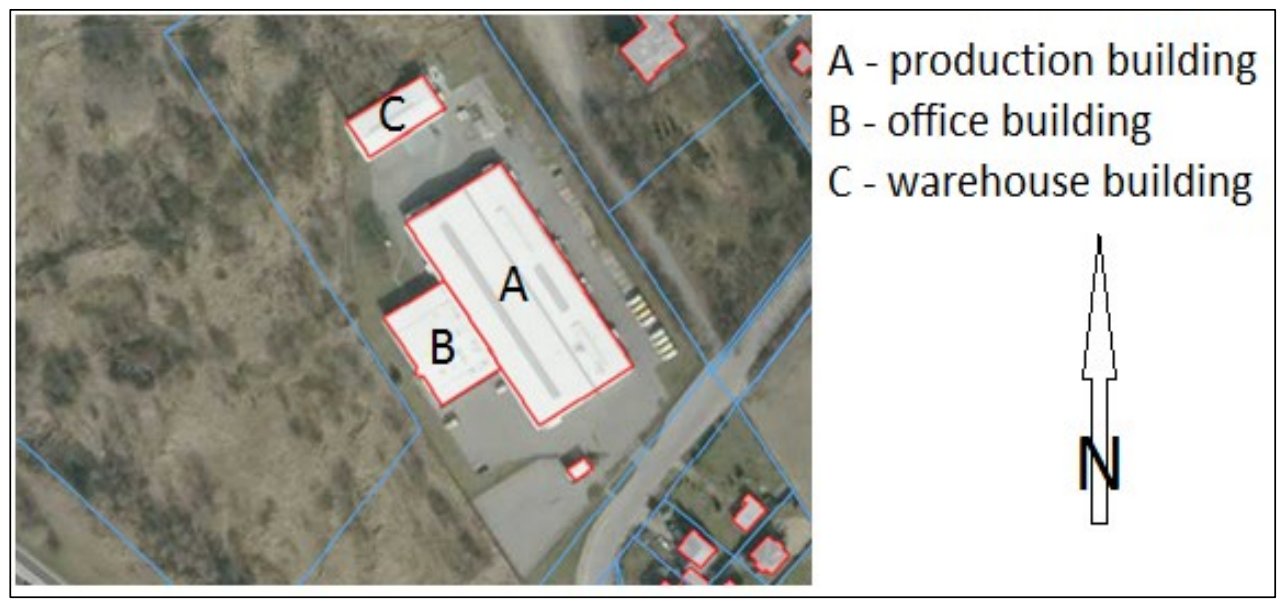

Fig. 1. View of the industrial facility along with the lot boundaries (marked in blue).

In terms of geomorphology, the lot is situated in the border area of the mesoregion Drwęca River Valley (315.13) and Chełmno Lake District (315.11). The area is part of the high, right-bank erosional terrace of the Drwęca River with outcrops built from Neogene expansive clay. The area is partially occupied by a site of storage of anthropogenic valley fills, moved from clay pits operated in the past.

Over a period of some thirty years, the slopes of the storage site have been overgrown with self-sown deciduous trees, Fig. 2.

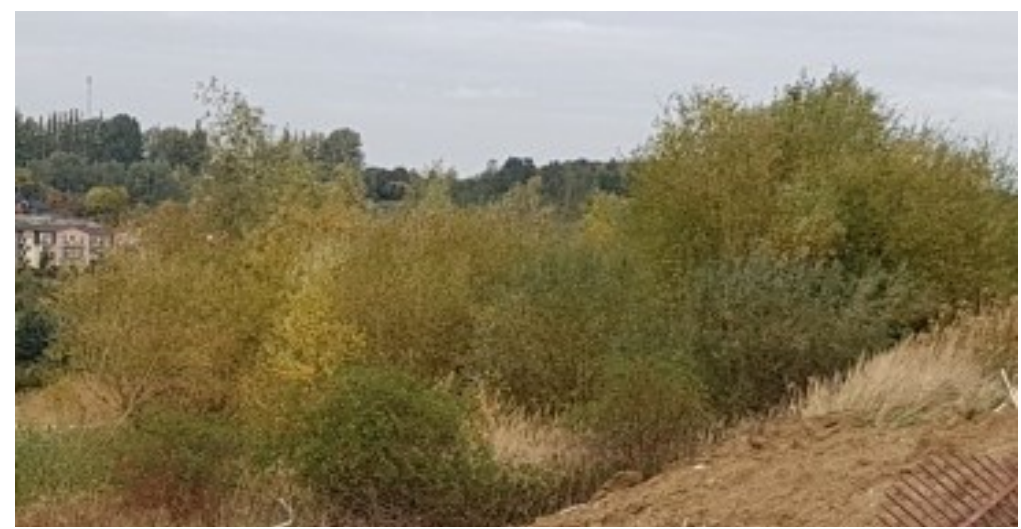

Fig. 2. Spontaneous reclamation of the slope with deciduous trees, after twenty years.

After completion of extraction of ceramic clay, the area was not properly and completely reclaimed (there are depressions with periodic stagnant water and slopes with inclination over $35^{\circ}$ ) with locally varying geodynamically active areas. 
According to the study of the Region of Kuyavia and Pomerania from 2010, entitled Landslides and areas endangered by mass movements in the Drwęca River Valley within the limits of the Region of Kuyavia and Pomerania, the lot was classified as an area in the $3^{\text {rd }}$ geotechnical category of stability of the slope. The slope constitutes the eastern boundary of the lot, Fig. 1, and it was not officially registered in the Landslide Counteracting System.

On part of the lot that was not disturbed and partially reclaimed, construction of production facilities of a big enterprise started in 1999. The production building was founded in the area not disturbed directly on continuous footings. The office building, located closer to the slope edge, was designed indirectly on reinforced concrete slab supported on Wolfsholz driven piles with $508 \mathrm{~mm}$ in diameter, [2] Fig. 3.

In 1998, the solution for founding the office building on Wolfsholz piles was a well thought out answer to stabilization of the subsoil and a slope for development of production facilities.

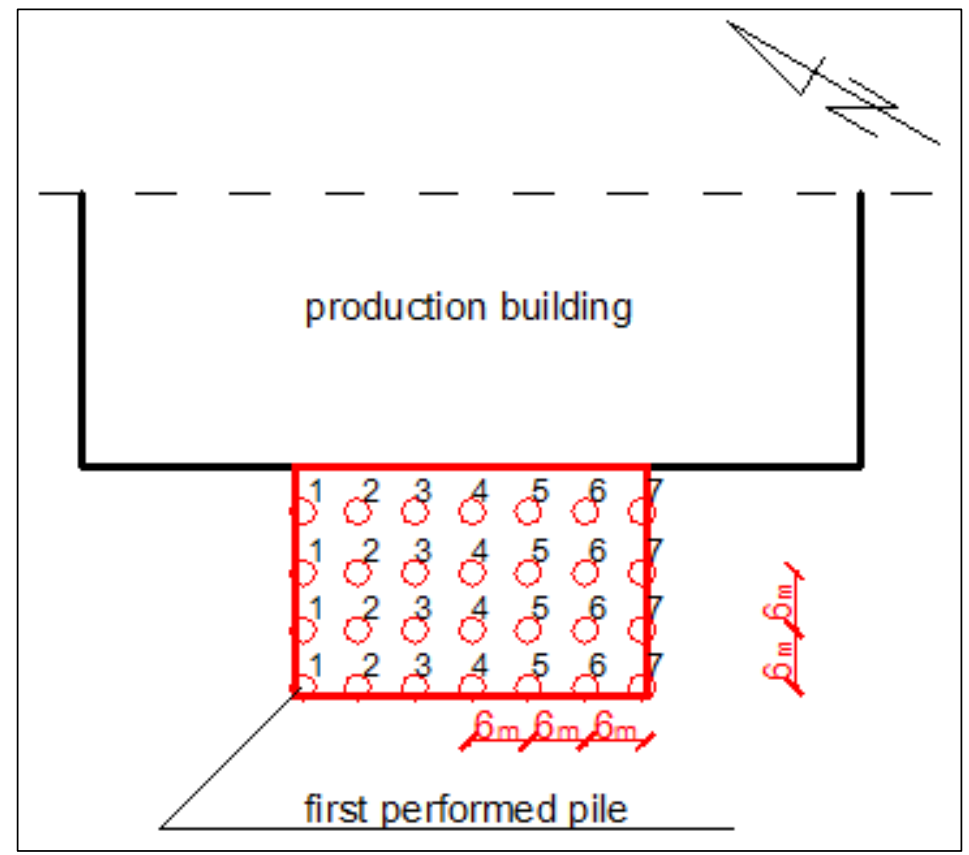

Fig. 3. Drawing with a layout of piles under the building according to [2].

To the maximum depth of 4.8 meters below ground level, an uncontrolled embankment in the form of mixture of clay, stone and compact sandy clay was reported, Fig. 4. Piles set in rows were founded in an undisturbed layer of rigid-plastic Neogene clay (degree of plasticity $I_{L}=0.05$ ). The design includes a variable length of piles ranging from $10.5 \mathrm{~m}$ to 16.5 running meters. Geotechnical and pile driving works performed during construction of the foundation and formation of the area were carried out under geotechnical supervision.

These days, in 2019, the lot is occupied by industrial facilities, Fig. 1, 3. The entrance from the community road to the plant is situated from the south, outside the slope. From the east and northeast there is undeveloped commercial land. Currently, works continue on leveling and preparation of lots for development with several industrial facilities. 


\subsubsection{Geotechnical conditions of the subsoil on the lot}

Soil and water conditions of the subsoil on the lot 15/10 were investigated in stages; in 1998 for the purpose of construction of the main building and in 2000 for the needs of foundation of the office building and compacting the top backfill of slopes. According to the findings of the investigation, the subsoil is represented by varied anthropogenic formations and heterogeneous, native, mineral sands and expansive clay with an admixture of marl.

The Holocene $\left(Q_{1}\right)$ is represented by:

- anthropogenic soils, which constitute a heterogeneous sand-clay-humus layer with thickness ranging from 0.9 to 3.8 (5 meters),

- colluvial soils are formed as a result of downslope creep of sands, locally fine and medium sands and excavated compacted silty clay.

The Pleistocene $\left(\mathrm{Q}_{2}\right)$ is represented by:

- alluvial-glacial soils formed as deposits of non-cohesive sands of varied granulation, consisting of fine, medium sands and gravel.

The NEOGENE $\left(\mathrm{N}_{1,2}\right)$ is built from Mio-Pliocene fluvial formations of the epicontinental basin. From a lithological point of view, this is compacted silty clay with an admixture of compacted grainy marl. The roof of the Mio-Pliocene clay is deposited on the ordinate about $73 \mathrm{~m}$ above sea level, whereas the bottom of the ceramic clay deposit was not drilled to 23 m below ground level, Fig. 4.

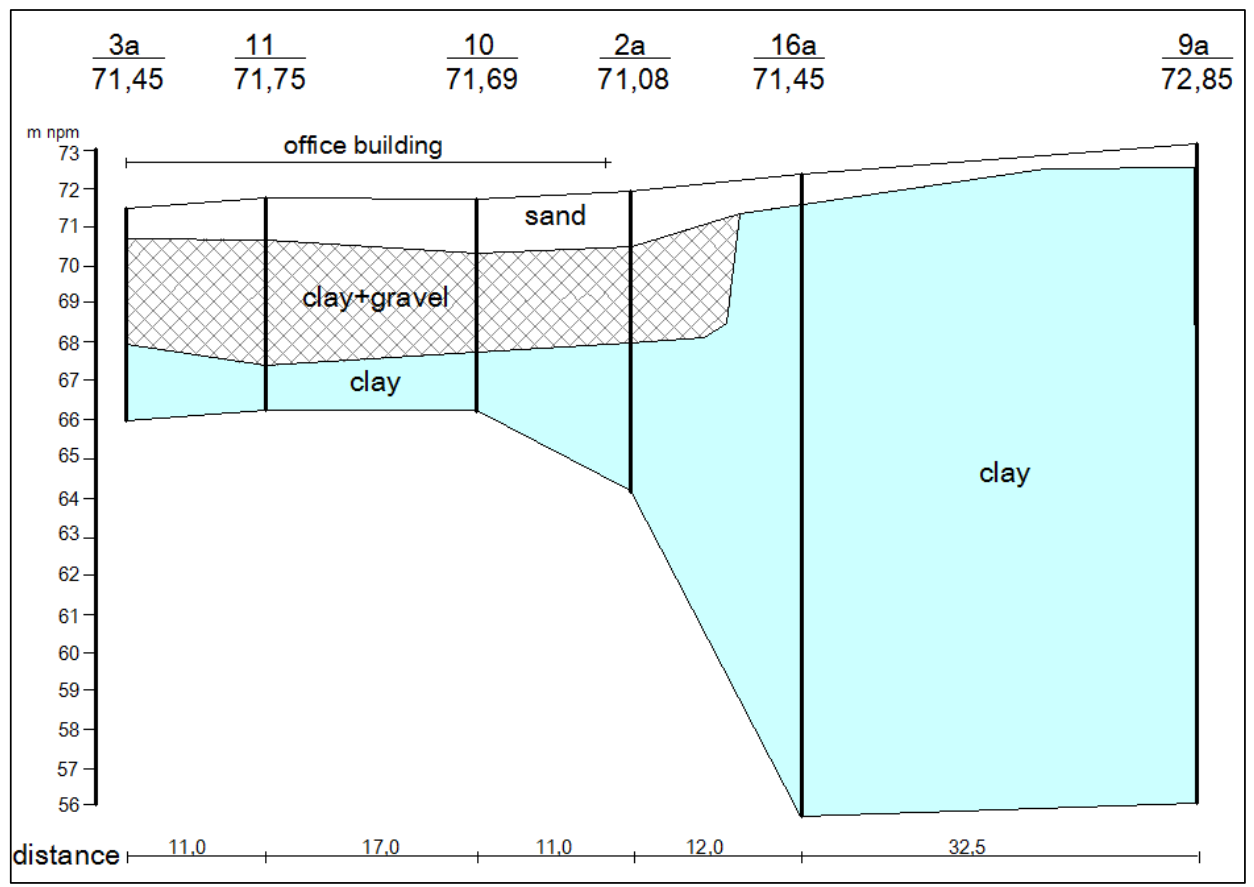

Fig. 4. Archival geological-engineering cross section according to [3].

In situ testing documented groundwater occurrence within anthropogenic sandy soils at the depth of $1.6 \mathrm{~m}$, i.e. on the ordinate $76.5 \mathrm{~m}$ above sea level. These waters were flowing in the southwest direction, in the form of seepages in the central and lower parts of the slope, flowing down to the surface of the excavation area. During studies conducted in 1998 - 2000, within anthropogenic soils and colluvium, numerous seepages were reported from compacted soils with interbedded deposits of sand. 
The description of geotechnical conditions looks as follows:

- $\quad$ stratum $M g$ - soils of uncontrolled embankment, anthropogenic (medium sands in a loose, medium compacted state, silty clay in a soft-plastic state);

- $\quad$ stratum $C$ - it is created from numerous local colluvial soils at an inclination and at the foot of the slope with thickness up to $1.7 \mathrm{~m}$ (built from a clay-sand mix with an admixture of organic parts). In general, they occur in a plastic and loose state.

Detailed, updated geotechnical data is presented on the geotechnical cross section, Fig. 4, and the value of geotechnical parameters is listed in Table 1, along with description of undisturbed subsoil on the testing site CPTU 1, on Fig. 5.

Table 1. List of geotechnical parameters of the subsoil according to CPTU 1.

\begin{tabular}{|c|c|c|c|c|c|c|c|c|c|c|c|c|c|}
\hline \multicolumn{7}{|c|}{ Test CPTU No.1 } & \multicolumn{7}{|c|}{ Water level: 2,0m } \\
\hline \multicolumn{2}{|c|}{ Depth } & Profile & $q_{0}$ & $\sigma_{\mathrm{vo}}$ & lo & IL & $\mathbf{q}_{\mathrm{n}}$ & $\beta_{q}$ & $\mathrm{Nm}$ & $\Phi$ & $C^{\circ}$ & Su & $\mathrm{M}_{0}$ \\
\hline \multicolumn{2}{|c|}{$[\mathrm{m}]$} & {$[-]$} & {$[\mathrm{MPa}]$} & {$[\mathrm{kPa}]$} & {$[-]$} & {$[-]$} & [MPa] & {$[-]$} & {$[-]$} & {$\left[{ }^{2}\right]$} & {$[\mathrm{kPa}]$} & {$[\mathrm{kPa}]$} & {$[\mathrm{MPa}]$} \\
\hline 0,0 & 0,9 & $\mathrm{nN}$ & 10,2 & 8 & 0,70 & - & 10,19 & 0,00 & - & $35^{\circ} 30^{\prime}$ & - & - & 50,0 \\
\hline 0,9 & 2,1 & $\mathrm{nN}$ & 3,6 & 28 & - & 0,16 & 3,57 & 0,00 & 29,5 & $28^{\circ} 50^{\prime}$ & 10 & 274 & 29,7 \\
\hline 2,1 & 3,6 & Clay & 0,5 & 55 & - & 0,43 & 0,45 & $-0,01$ & 2,4 & $10^{\circ} 40^{\prime}$ & 16 & 25 & 4,1 \\
\hline 3,6 & 4,0 & Clay & 1,0 & 74 & - & 0,40 & 0,92 & $-0,05$ & 6,8 & $18^{\circ} 30^{\prime}$ & 9 & 57 & 9,8 \\
\hline 4,0 & 4,8 & Clay & 1,1 & 86 & - & 0,07 & 0,99 & $-0,07$ & 5,1 & $16^{\circ} 10^{\prime}$ & 24 & 55 & 8,9 \\
\hline 4,8 & 5,8 & Fine sand & 18,1 & 103 & 0,85 & - & 17,98 & 0,00 & - & $37^{\circ} 50^{\prime}$ & - & - & 83,2 \\
\hline 5,8 & 7,3 & Silit & 7,8 & 128 & - & 0,01 & 7,65 & $-0,01$ & 44,9 & $31^{\circ} 40^{\prime}$ & 15 & 544 & 64,2 \\
\hline 7,3 & 8,0 & Clay & 3,3 & 151 & - & 0,06 & 3,09 & $-0,04$ & 17,4 & $25^{\circ}$ & 16 & 193 & 32,1 \\
\hline 8,0 & 9,2 & Clay & 1,6 & 170 & - & 0,03 & 1,41 & $-0,08$ & 6,0 & $17^{\circ} 20^{\prime}$ & 25 & 78 & 13,0 \\
\hline 9,2 & 10,5 & Clay & 2,4 & 195 & - & 0,01 & 2,19 & $-0,06$ & 8,8 & $20^{\circ} 20^{\prime}$ & 29 & 122 & 19,6 \\
\hline
\end{tabular}

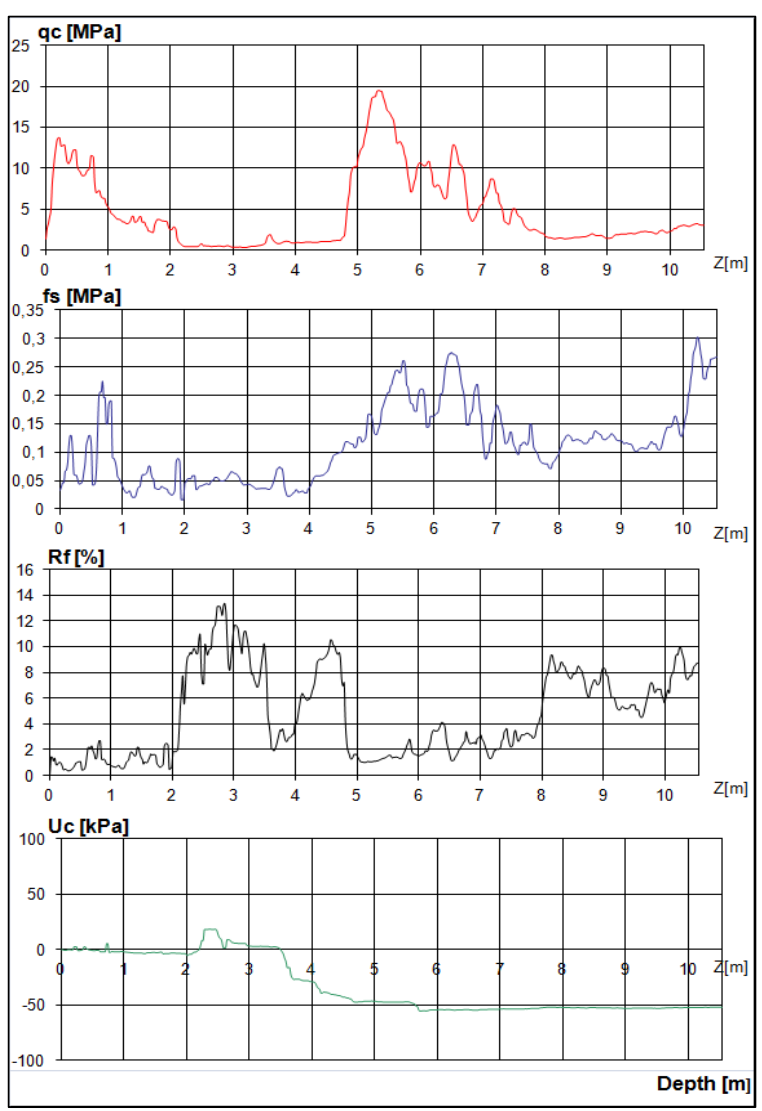

Fig. 5. Sample CPTU 1 probe testing on the slope. 


\subsection{Geotechnical description of landslide development}

The production facility and office building on the lot no. 15/10 were designed in 2000 and built in accordance with contemporary construction practices. During the design stage, all necessary studies were conducted, including global and local stability analyses of the slope, serving as the eastern boundary of the lot, [3].

It was stated that the ground massif until the border outlined by the fence and beyond it constitutes a potential landslide, thus protective cascading terraces were made as counter fill. An additional, deep reinforcement of the slope stability was foundation of the office building on Wolfsholz piles.

Precipitation and thaw water management have been organized in a proper way on the lot. Water has been collected in accordance with the terms of the water-legal permit, conveyed by drainage to the sump well situated in the proximity of the western fence of the lot. It is used to water plants and trees and is also used for soil infiltration in green areas.

Until 2017, slopes, fence and buildings were stable, and monitoring showed no symptoms of mass movement activities, [3].

In June 2017, the owner of the neighboring western building lot, i.e. lot no. xx/11, started without any arrangements [6] - earthworks, preparing the land for its own investment project. Cleaning works included initially tree clearing, Fig. 2, expanded successively by extensive levelling of terrain, including entries and operation of heavy equipment on the lot no. 15/10, increasing the angle of inclination of the slope and undercutting the base of the slopes, Fig. 6 and 7.

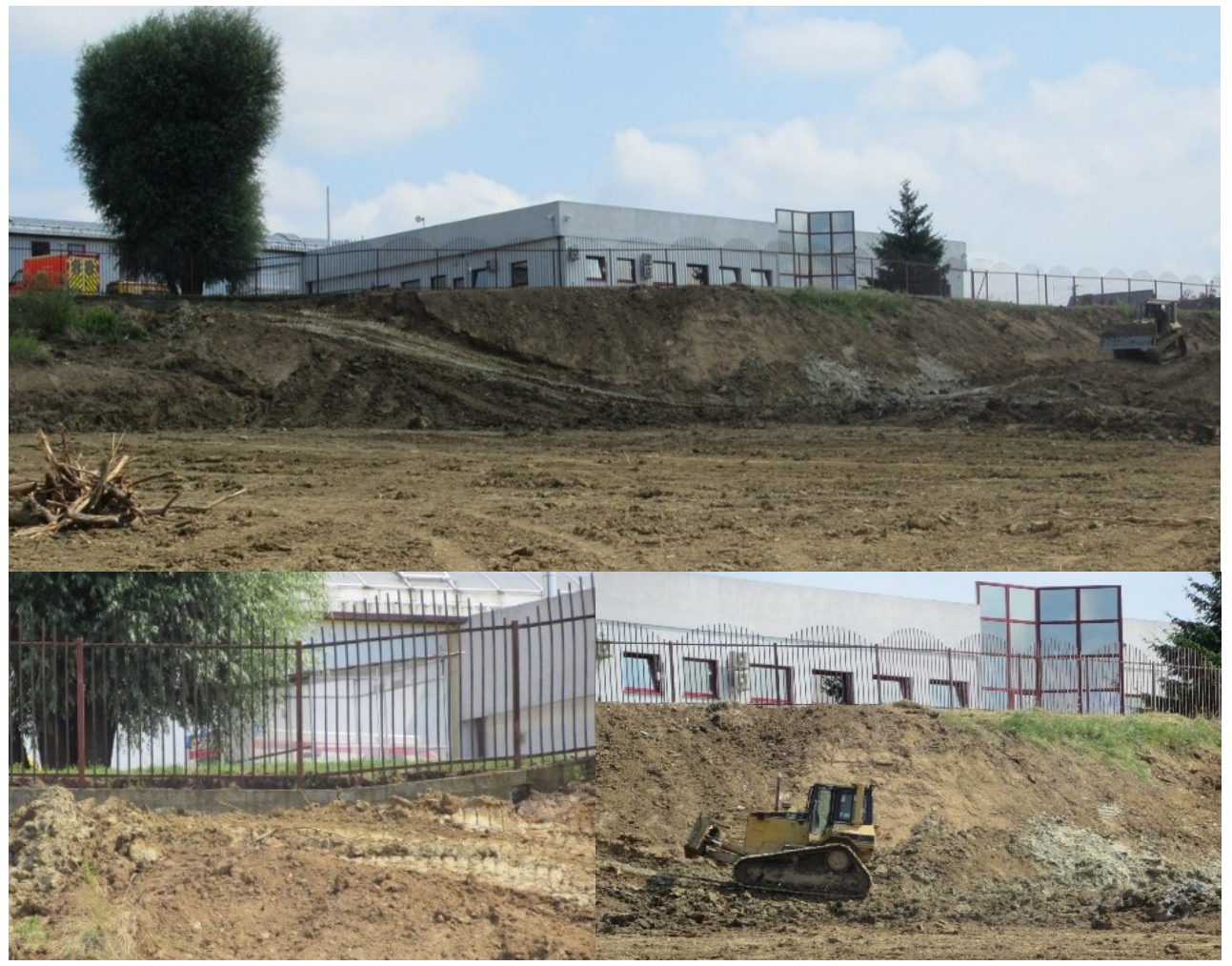

Fig. 6. Sample CPTU 1 probe testing on the slope.

Fig. 7. Beginning of landslide - caused by undercutting of the slope. Visible collapse of the fence. 
The owner of the lot no. 15/10 notified the Office on unauthorized tree removal by third parties on its lot. An on-site visit with representatives of the Office was performed along with photographic documentation after clearing trees by third parties on the slope within the limits of the lot no. 15/10, Fig. 2, 6.

The office discontinued the proceedings concerning unauthorized tree removal on the lot, justifying this fact by lack of sufficient evidence and no perpetrator responsible for clearing trees.

On July 30, due to continuing earthworks and dangerous disturbance of the slope stability by workers performing leveling of the construction lot no. $\mathrm{xx} / 11$, during leveling works, the County Inspectorate for Building Supervision was notified about a threat of construction disaster. During that time, there was a landslide along with shifting of the fence and discharge of waters from mains, threatening directly the foundation of the existing office building and production facility on the lot no. 15/10, Fig. 8.

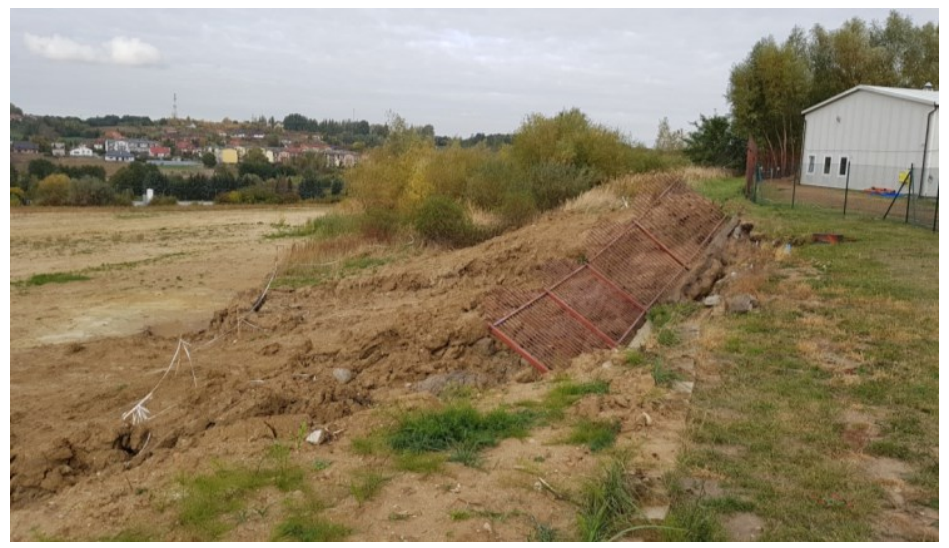

Fig. 8. Landslide triggering - after undercutting the slope. Visible collapse of the top backfill, development of a niche and destruction of the fence.

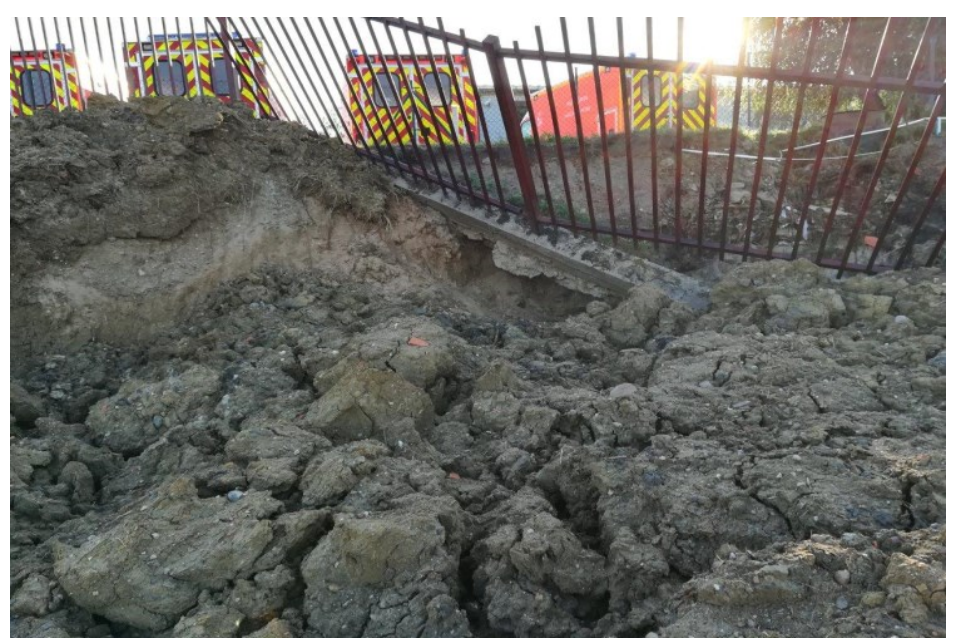

Fig. 9. Results of destruction of the top backfill of the slope as a result of undercutting the slope on the neighboring lot.

It was determined that from the lot no. $15 / 10$ and the slope running alongside the boundary with the lot no. xx/11, over 2500 cubic meters of soil were removed during leveling, which is illustrated by the panoramic view, Fig. 6. 
Development of surface movements of the ground massif and a down-slide movement of the slope led to destruction of the fence, interruption of continuity of the drainage system, and formation of new zones in tension, run-off and landslides of colluvial masses, Fig. 10.

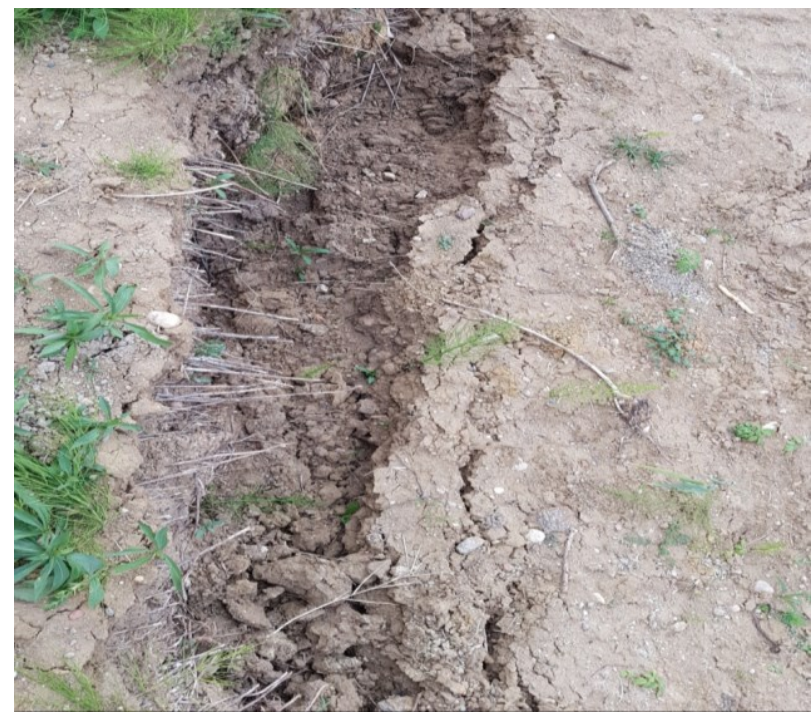

Fig. 10. View of surface cracks confirming the progressing instability of the slope outside the existing wedge.

The owner of the production lot 15/10 reapplied to the Office with a proper motion to institute proceedings regarding unauthorized earth moving activities, posing a threat to public life and health as well as property. In the answer, he was notified that the case was transferred by the commune head to the County Inspector for Building Supervision (PINB).

PINB performed an appropriate inspection of the real estate and construction properties on the lot no. $\mathrm{xx} / 11$ in relation to the rapid landslide on the slope on the lot no. 15/10.

Summary of the formal activities. Until now, i.e. the year 2019, solving the problem related to disturbance of stability of the slope on the lot no. 15/10, as a result of unauthorized leveling activities, led to further instability in subsoil, posing serious risk of construction disaster, affecting stability of production facilities and office buildings founded on the lot no. $15 / 10$. The stage of administrative procedure was formally achieved, i.e. completion of the inspection of real estate and construction properties on the lot no. $x x / 11$. The owner of the lot no. 15/10, not waiting for the decision of administrative bodies, has undertaken appropriate measures to remedy landslide problems and to secure the slope, preventing further deterioration of the industrial facility.

\section{Determination of the geotechnical problem}

Based on studies and analyses on determination of the causes that led to geotechnical failure of the construction subsoil on the lot no. 15/10, it can be confirmed that the principal factor that has contributed to destruction was the irresponsible leveling of the land in the area of the wedge and base of the slope. Incorrect performance of an extensive range of leveling works, clearing trees and considerable earthworks on the neighboring lot, no xx/11, led to undercutting of the slope that existed for over 30 years and was secured in 1998. It resulted in disturbance of the local geostatic balance and uncontrolled movement of the landslide mass along with destruction of the protection systems and underground drainage system. 


\subsection{Landslide stability analysis}

Immediately after the geotechnical failure, in September 2018, verifying geotechnical testing of the subsoil was conducted. One of the tests was statistical CPTU method at the top edge and the foot of the bottom edge, and in the area of the undisturbed slope. Stability analysis was carried out in three distinct, active cross sections outlined in the area, Fig. 11 and $12,[4,5]$. Figure 11 shows general data, extent and geometry of the landslide in relation to the office building and industrial facility.

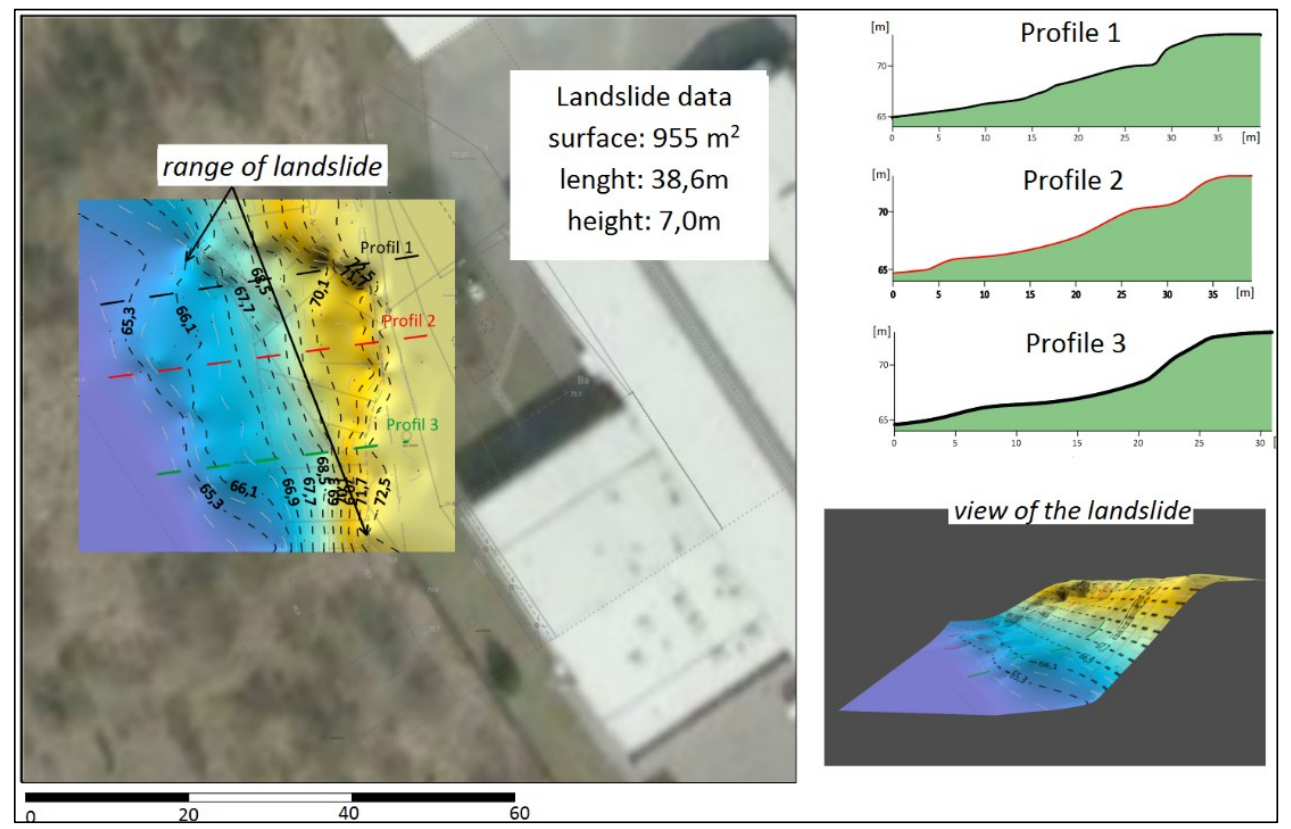

Fig. 11. Extent and profiles of the landslide formed on the lot no. $15 / 10$ in the proximity of buildings.

Sites of CPTU tests for statistical analysis were located in the zone of slope undercutting and disturbance of stability of the slope as well as the initial, stable area. In addition, the extent of active, newly formed colluviums was inventoried, Fig. 12.

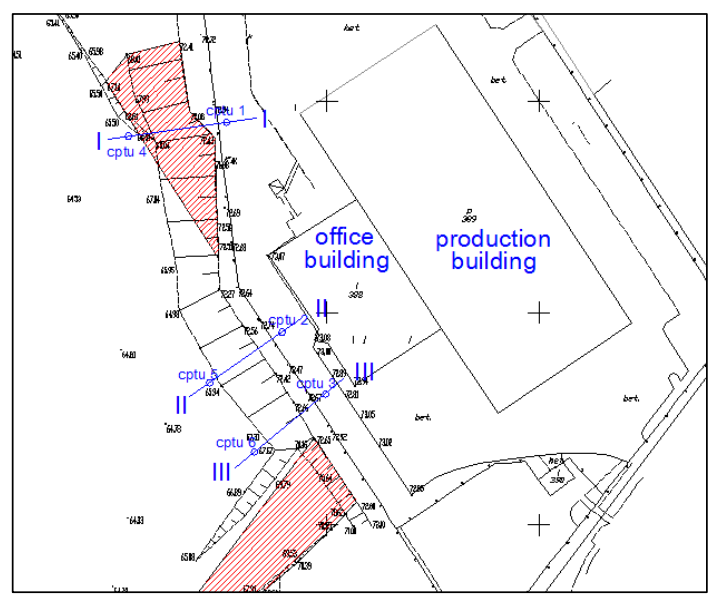

Fig. 12. Extent of newly formed colluviums and testing sections of the landslide on the lot no. 15/10 in the proximity of buildings 
Slope stability analysis was performed with the use of simulation methods, using numerical values of parameters obtained from direct geotechnical testing in three cross sections shown in Figure 12. The stability analysis considered the original stability of the slope, additional flow pressure, and active drainage systems. The final calculations of the slope stability analysis also used data from the study [10]. The analysis assumed effective parameters deriving from 6 cross sections of CPTU testing Fig. 5. Fig. 13 to 16 show consecutive results of calculations in cross sections I-I, II-II and III-III in the intact and original condition, in which mass movement of the slope was triggered, [1].

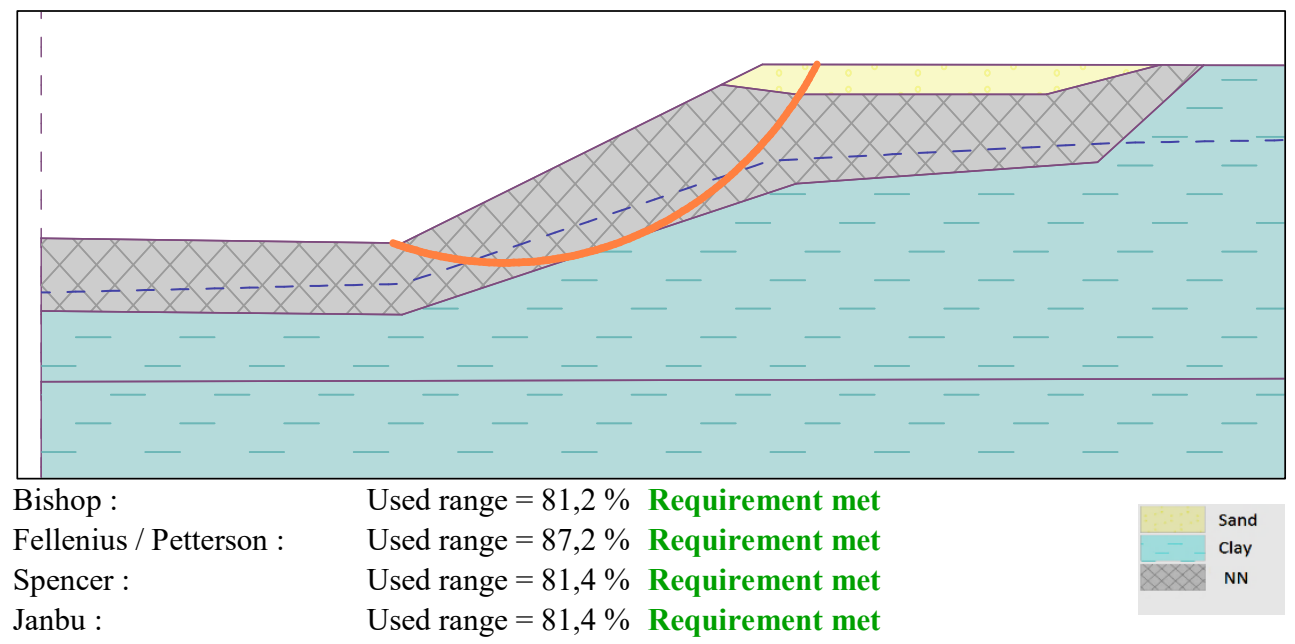

Fig. 13. Cross section of the slope I-I on the site of landslide. The original condition. Simulation with additional water flow pressure - stable slope.

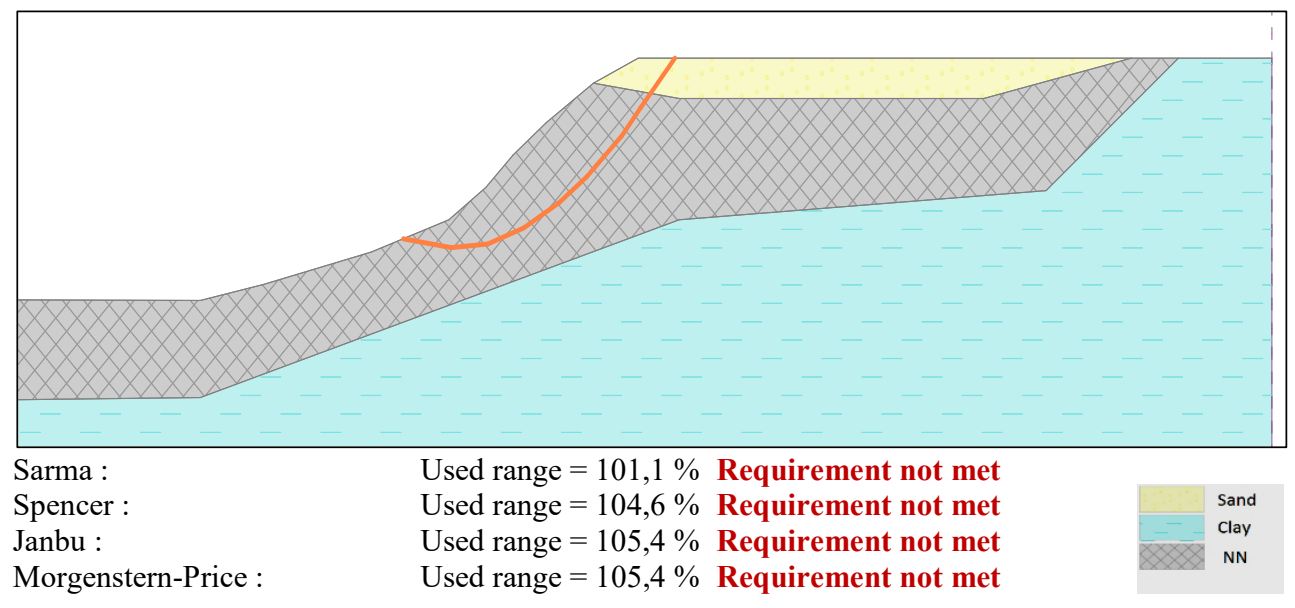

Fig. 14. Results of slope stability analysis I-I on the site of landslide occurrence, Fig. 8, 9, without taking into account flow pressure of groundwater. Unstable slope. 


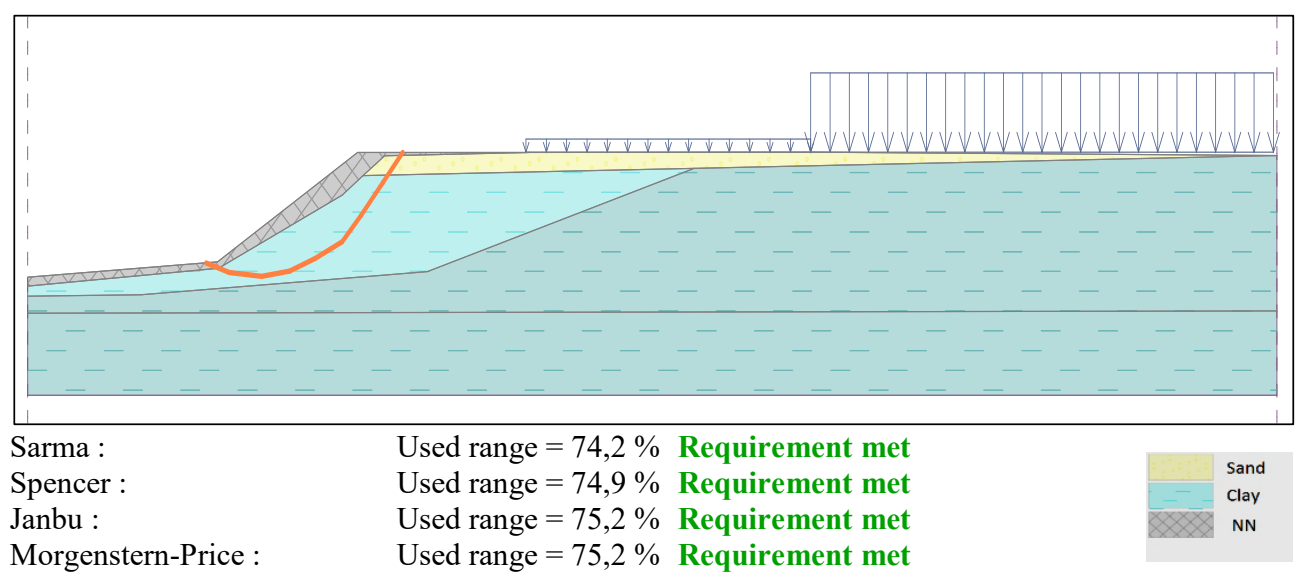

Fig. 15. Cross section II-II in the proximity of the existing office buildings. Despite undercutting of the slope, the massive is stable. There is no threat to the office building, Fig. 12, 8.

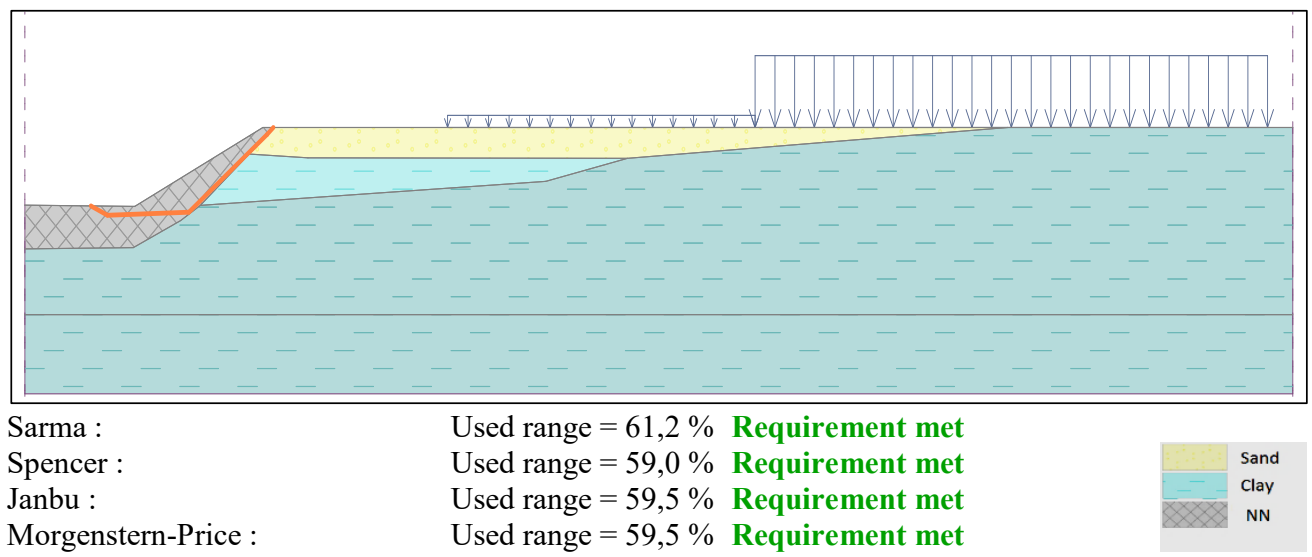

Fig. 16. Cross section of the slope III-III alongside the existing buildings. Despite undercutting of the slope on the neighboring lot, the landslide is stable, Fig. 9, 12. There is no threat to the office building.

\subsection{Geotechnical conclusions from the slope analysis}

Based on the results of changes in soil conditions and calculations, we can specify in general the following causes for loss of stability in the edge zone of the slope:

- $\quad$ direct cause, which triggered disturbance in geostatic balance and caused movement of massif along with occurrence of the local landslide, i.e. unadjusted and incorrectly performed leveling works and undercutting of the slope on the neighboring lot,

- $\quad$ secondary causes, destruction of parts of underground infrastructure and utility systems, including storm drainage systems, retaining wall of the fence, destruction of counter fills securing the slope and disturbance of underground electrical system and monitoring system,

- other causes, clearing trees stabilizing and protecting the slope against erosion, disturbance of local water conditions within the limits of the Drwęca River Valley and change in the direction of storm water runoff, backfilling numerous water reservoirs in the excavation site,

- omission, nonperformance, after geotechnical failure, any works securing the slope or performance of such works incorrectly, despite the fact that they were necessary. 
Based on results of analyses and stability calculations of the slope, as well as direct monitoring in the area (September 2018), it was stated that without design and performance of proper securing works, the local landslide that occurred on the site is in the limit state of increasing trend of random activity, Fig. 10.

In addition, tree removal across the area and change in the direction of storm water runoff cause concentrated increase in the erosive activity. Changes caused by leveling and backfilling of ponds - despite reprimands given to contractors performing earthworks and the owner - led to change in the direction of local groundwater flow. It will undoubtedly have a negative impact on the neighboring lots (flooding and disturbance in subsoil stability), leading to a currently unpredictable extent of mass movements.

These days, the office building and production facility are not threatened by movements of the landslide and they can be operated. However, repair works should start immediately based on a properly prepared design for securing the slope and control of water and soil relationships. Other urgent activities that need to be undertaken include restoration and repair of the leaking storm drainage system.

\section{Proposals for securing the slope}

Reviewing geotechnical conclusions drawn from the subsoil stability analysis and the current threat level of the buildings situated on the lot no. $15 / 10$ as well as projected development on the neighboring lots, there is a proposal to secure the slope using one of the actual realistic alternatives:

- Alternative no. 1, building of the slope in accordance with the original topography on the lots no. $15 / 10$ and $\mathrm{xx} / 11$,

- Alternative no. 2, rebuilding of the slope with a different inclination, in the technology of a slope reinforced with geosynthetics within the limits of the Investor's lot no. 15/10.

In accordance with the results of surveying measurements, a geometric model was developed along with calculation of soil mass volume within the range of the landslide [3]:

$\begin{array}{ll}- & \text { Landslide area }-955 \mathrm{~m}^{2}, \\ \text { - } & \text { Height } H=7 \mathrm{~m}-\text { average } 3.5 \mathrm{~m}, \\ \text { - } & \text { Width around - about } 33.5 \mathrm{~m},\end{array}$

\subsection{Alternative no. 1 for rebuilding of the slope according to the original topography}

According to archival documentation [3], plans include restoration of the slope to its original topography - Fig. 17.

Work estimate in Alternative no. 1:

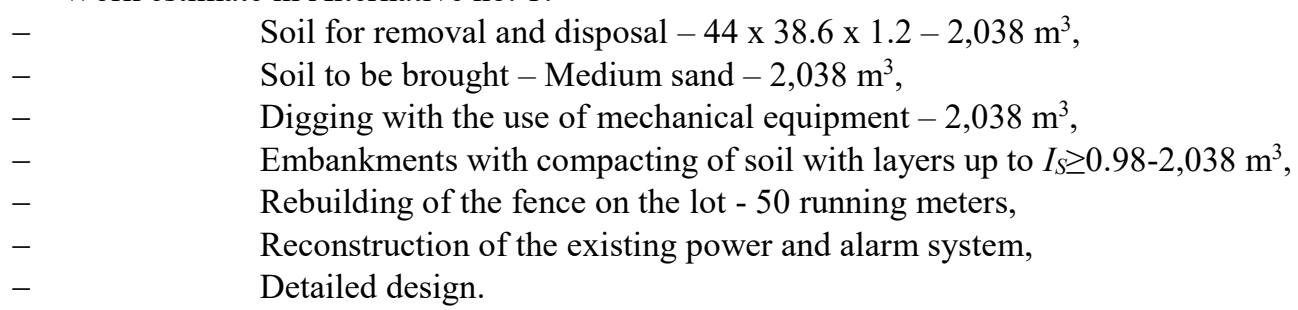

In order to perform the works mentioned above, it is assumed that they will be carried out on the neighboring lot. 


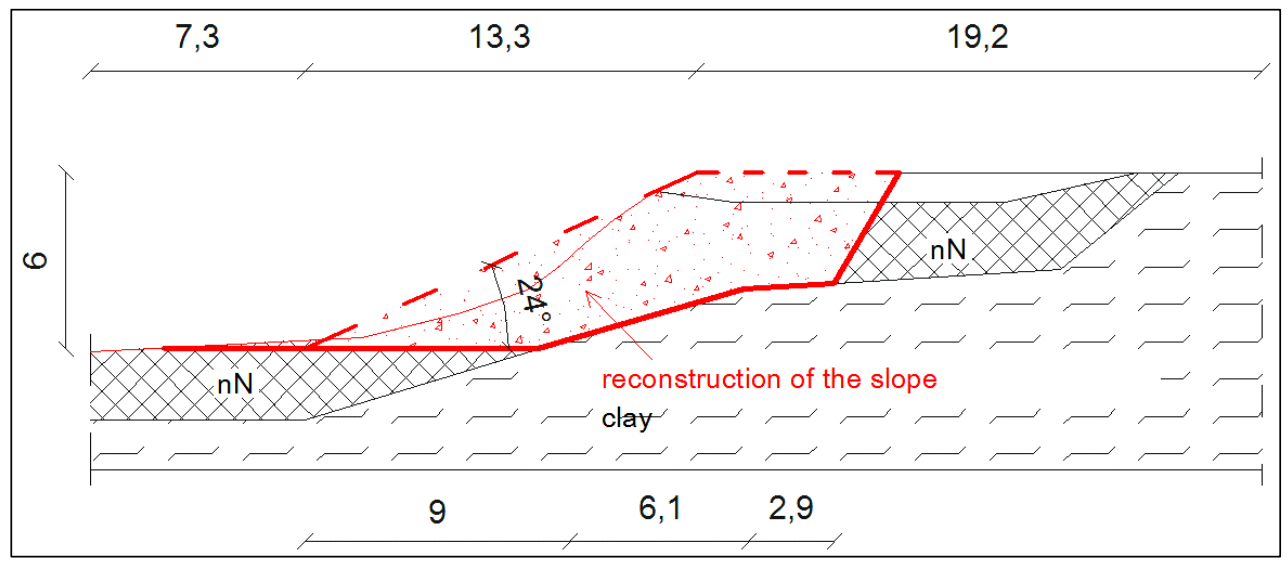

Fig. 17. Rebuilding of the slope according to Alternative no. 1. Restoration of the lot to its original topography, $15 / 10$ and $\mathrm{xx} / 11$.

Before beginning earthworks, an appropriate detailed design has to be made and an approval received from the owner of the neighboring lot.

\subsection{Alternative no. 2 for rebuilding of the slope in geosynthetic reinforced soil}

When there is no approval from the owner of the neighboring lot, whose works led to landslide occurrence, it is assumed that the slope will be rebuilt alongside the limits of the lot no. $15 / 10$ - Fig. 18 , without interference in the neighboring lot. Considering the fact that it is impossible to ensure stability of the slope, the design includes reinforcement of the slope with the use of geosynthetics.

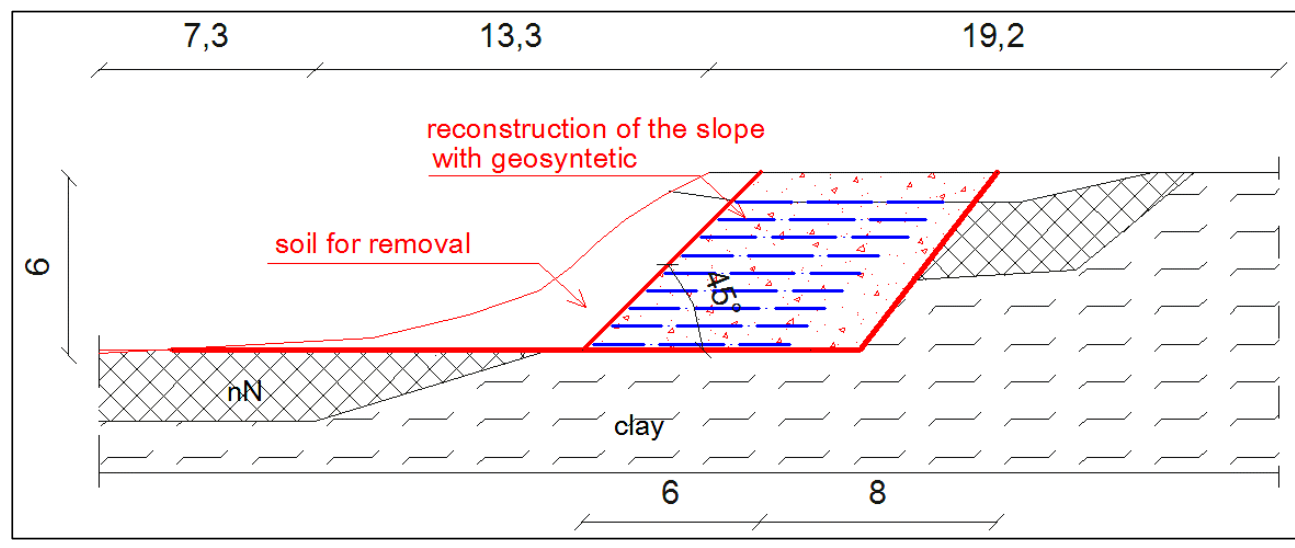

Fig. 18. Rebuilding of the slope according to Alternative no. 2. Restoration to the limits of the lot no. $15 / 10$.

Work estimate in Alternative no. 2:

Soil for removal and disposal - $83.3 \times 38.6 \times 1.2-3,860 \mathrm{~m}^{3}$,

Soil to be brought - Medium sand - $52.2 \times 38.6 \times 1.2-2,420 \mathrm{~m}^{3}$,

$-$

- $\quad$ Digging with the use of mechanical equipment $-3,860 \mathrm{~m}^{3}$,

- $\quad$ Embankments with compacting of soil with layers up to $I_{S} \geq 0.98-2,420 \mathrm{~m}^{3}$,

- Installation of the bottom mattress PET $400 / 50 \mathrm{kN}$, thickness $60 \mathrm{~cm}-1,000 \mathrm{~m}^{2}$, 
Installation of reinforcement inserts PET $100 / 50 \mathrm{kN}-3,000 \mathrm{~m}^{2}$,

Rebuilding of the damaged fence - 50 running meters,

Reconstruction of the damaged power and alarm systems,

Detailed design.

\section{Final conclusions and summary}

Test results and geotechnical analyses of the landslide that occurred due to anthropogenic causes allow to formulate the following final conclusions:

The direct and principal cause for generating mass movement of the slope and occurrence of the landslide was irresponsible conducting of leveling works, illegally on the neighboring lot and the Investor's lots. Works were carried out without specialized geotechnical supervision and without appropriate activity of an administrative body - despite formal activities of the owner of the neighboring lot exposed to risk.

The causes are secondary in nature, related to negligent activity of the contractor with the passive knowledge of the Office [3].

Environmental damages that have been reported, including destruction of parts of underground infrastructure and utility systems, retaining wall of the fence, destruction of counter fills securing the slope and disturbance of underground electrical system and monitoring system, and clearing of trees stabilizing and protecting the slope against erosion, led to permanent disturbance of local soil and water relationships within the limits of the Drwęca River Valley that is under protection.

Removal of trees on the slope and change in the direction of storm water runoff can lead to development of subsequent, currently unpredictable mass movements.

Presently, the office building and production facility are not under threat and they can be operated. However, repair works of underground infrastructure should start immediately.

It is recommended to rebuild the slopes according to Alternative no. 1, after previous receiving of an approval from the owner of the neighboring lot $\mathrm{xx} / 11,[3]$.

Ceramic clay was extracted illegally from the lot. It is classified as useful mineral and its extraction is licensed in accordance with the Geological and Mining Law.

\section{References}

1. Software: GEO5 - Slope Stability /version 5.2018.34D/security key 6729/1/Pracowania Inżynieryjno-Geologiczna/Engineering-Geological Company, Copyright 2018 Fine r.o. All Rights Reserved.www.finesoftware.eu

2. Design Project: M.K. Kumor, K. Szpakowski, Design of bearing capacity of Wolfsholz piles for the foundation of the company support building. (Pracownia InżynieryjnoGeologiczna/ Engineering-Geological Company, Bydgoszcz, 2000) [in Polish]

3. Design Project: Ł. Kumor, M.K. Kumor, J. Lorkowski, Geotechnical expertise determining the causes of slope destruction, technical condition and stability of the disturbed slope on the premises of the company, (Pracownia InżynieryjnoGeologiczna/Engineering-Geological Company, Bydgoszcz, 2018) [in Polish]

4. PN EN 1997-1:2008 Eurocode 7 Geotechnical Design, part 1: General principles

5. PN EN 1997-2:2009 Eurocode 7 Geotechnical Design, part 2: Ground investigation and testing and PNEN 1997-1:2009/AC:2010; PN EN 1997-1:2009/Ap1:2010

6. Resolution of the Minister of Transport, Construction and Maritime Economy of April 25, 2012 regarding determination of geotechnical conditions for the foundation of buildings. (Journal of Laws, Warsaw, April 27, 2012, art. 463) [in Polish] 